\title{
Robust sensorless load angle control for stepping motors
}

\author{
Stijn Derammelaere, Florian Verbelen, Kurt Stockman \\ Department of Industrial System and Product Design, Ghent University Campus Kortrijk, Belgium
}

\begin{abstract}
In industry, the bulk of the stepping motors is driven in open loop full-step mode with maximum current to avoid step loss. This results in noisy operation due to torque ripples and a poor energy-efficiency. To tackle these problems the current current level at which the stepping motor is driven can be reduced to an optimal level. In this paper, a sensorless load angle controller is proposed and implemented to optimise the drive current level. However, reducing the current level results in a diminished torque margin for load disturbances. In this paper, a countermeasure to enhance the robustness of the sensorless load angle controller against torque disturbances is proposed and assessed trough measurements.
\end{abstract}

\section{INTRODUCTION}

Stepping motors are very well suited for positioning at lowpower, typically below $0.75 \mathrm{~kW}$. The operating principle of a hybrid stepping motor [1] is illustrated in fig. 1. The multitoothed stator is equipped with windings. The multi-toothed rotor on the other hand is magnetized by means of permanent magnets. When a full-step command is given, the excitation of one phase is released while another is excited. In this way, the stator current excitation vector will rotate over 90 electrical degrees. As a result the rotor will move over one fullstep. By counting these step commands, open loop positioning is made possible. However, basic open-loop drive algorithms such as full-, half- and micro-stepping result in torque and speed ripples, noise, vibrations, a poor energy efficiency and no control on step loss [2], [3].

More advanced control strategies, proposed in literature [4][7], manipulate the angular position of the current excitation vector. This means positioning by sending step command pulses is no longer possible. On the other hand, the control structure [8], used in this paper will only manipulate the current level. This means the relation between the step command pulses and current excitation vector stays the same as in standaard stepping motor drive algorithms. This resulting in a more convenient possible implementation in industry. However, this method, where the current level is optimised, results in a diminished robustness against load torque disturbances resulting in step loss. Therefore, this paper proposes a mechanism to improve the robustness of a stepping motor system driven at optimal current levels. This mechanism will allow to optimize the efficiency by current reduction while there is still a certain robustness against load torque disturbances.

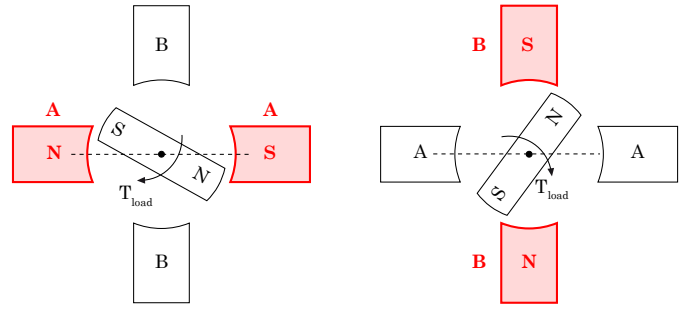

(a) Full Step principle

Stator

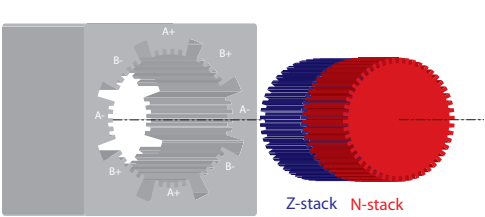

(b) Hybrid stepping motor construction

Fig. 1. Stepping motor principle

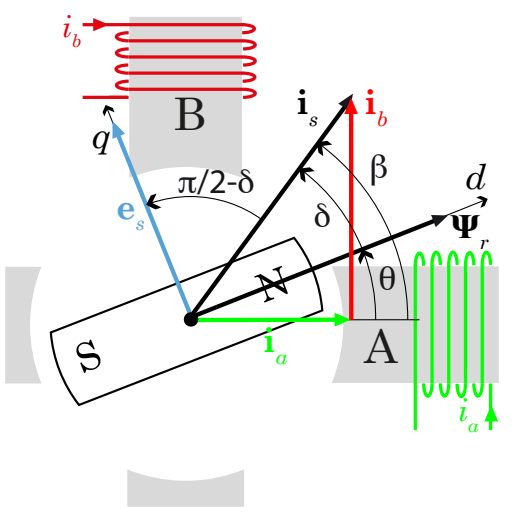

Fig. 2. Back-EMF, current and flux vectors

\section{LOAD ANGLE}

The formula describing the electromagnetic motor torque is essential to have the necessary understanding in the stepping motor drive principle. The electromagnetic torque vector $\mathbf{T}_{\text {motor }}$ can be determined based on the interaction between the stator flux linkage space vector $\boldsymbol{\Psi}_{s}$ and the stator current space vector $\mathbf{i}_{s}$ [9], both depicted in Fig. 2

978-1-4799-8805-1/15/ \$31.00 @2015 IEEE 


$$
\mathbf{T}_{\text {motor }}=\mathbf{\Psi}_{s} \times \mathbf{i}_{s}
$$

Neglecting saturation, the stator flux linkage space vector $\boldsymbol{\Psi}_{s}$ can be written as the sum of the stator flux linkages, established by the two stator currents and the permanentmagnet rotor flux $\boldsymbol{\Psi}_{r}$. In the $d q$-reference frame fixed to the rotor flux, illustrated in Fig. 2, the electromagnetic torque can be written as:

$$
\mathbf{T}_{\text {motor }}=\left(\mathbf{\Psi}_{r}+\mathbf{i}_{d} \cdot L_{d}+\mathbf{i}_{q} \cdot L_{q}\right) \times \mathbf{i}_{s}
$$

The electromagnetic torque value can be written as a function of $i_{s}$ and the load angle $\delta$, defined as the angle between $\mathbf{i}_{s}$ and the rotor flux $\boldsymbol{\Psi}_{r}$ :

$$
T_{\text {motor }}=\Psi_{r} \cdot i_{s} \cdot \sin (\delta)+\frac{L_{d}-L_{q}}{2} \cdot i_{s}^{2} \cdot \sin (2 \delta)
$$

The first term in (3) describes the torque generated by the interaction between the permanent-magnet rotor flux $\boldsymbol{\Psi}_{r}$ and the stator current $\mathbf{i}_{s}$. This term depends on the sine of the load angle $\delta$. Because of the multitoothed rotor and stator construction of a hybrid stepping motor, the reluctance effect will increase the maximum electromagnetic torque. This reluctance effect is represented by the second term in (3) and varies sinusoidally with twice the load angle $\delta$. To quantify both effects, the motor torque is measured, using the test rig depicted in Fig. 5. While the rotor is blocked the load angle $\delta$ is modified by changing the phase current setpoints $i_{a}^{*}$ and $i_{b}^{*}$. For a current amplitude of $60 \%$ and $100 \%$ of the nominal current, measurement results are given in Fig. $3^{1}$. The dominant torque component is the component generated by the permanent-magnet effect.

To illustrate the behavior of the load angle, measurements are performed at different speed and torque levels at maximum current. Fig. 4 illustrates these results for a half-step operation mode. The load angle increases when the load torque increases. A higher rotational speed also results in an increased load angle. The latter is due to a higher friction torque in the test set-up.

\section{LOAD ANGLE ESTIMATION}

Using Lenz's law the back-EMF voltage vector $\mathbf{e}_{s}$, induced by the rotor flux $\boldsymbol{\Psi}_{r}$, can be written as:

$$
\mathbf{e}_{s}=C \cdot \frac{\mathrm{d} \boldsymbol{\Psi}_{r}}{\mathrm{~d} t}
$$

This implies a phase lead of $\pi / 2 \mathrm{rad}$ between the backEMF vector $\mathbf{e}_{s}$ and the flux vector $\boldsymbol{\Psi}_{r}$ as illustrated in Fig. 2. From Fig. 2 it follows that the angle between the current vector $\mathbf{i}_{s}$ and the back-EMF vector $\mathbf{e}_{s}$ is $\pi / 2-\delta$. Because the current can be measured easily, estimating the load angle can

\footnotetext{
${ }^{1}$ All angular values are given in electrical radians. For a machine consisting of $p$ pole pairs this means the actual mechanical angle $\theta_{\text {mech }}=\theta / p$
}

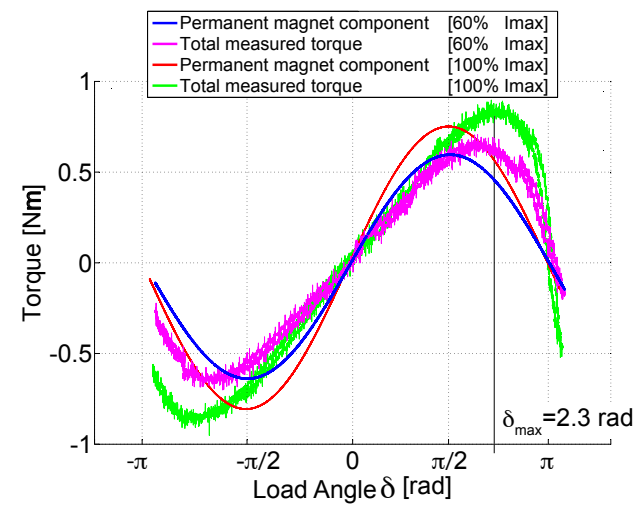

Fig. 3. Measured torque - load angle relation for $60 \%$ and $100 \%$ nominal current $I_{\max }$

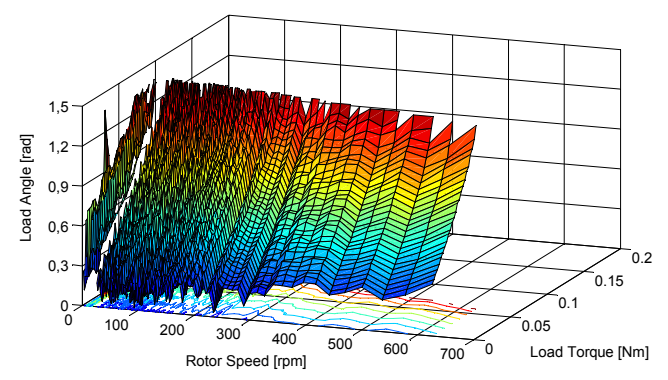

Fig. 4. Measured load angle $\delta$ for different torque and speed setpoints at nominal current

be reduced to a problem where the back-EMF signal has to be estimated.

The stator phases can be modeled as [10]:

$$
u_{s}=R_{s} \cdot i_{s}+L_{s} \cdot \frac{\mathrm{d} i_{s}}{\mathrm{~d} t}+e_{s}
$$

[8], [11] suggests to write (5) in the frequency domain:

$$
E_{s}(j \omega)=U_{s}(j \omega)-j \omega \cdot L_{s} . I_{s}(j \omega)-R_{s} . I_{s}(j \omega)
$$

Simulations and measurements discussed in [8], [11] show that the load angle can be estimated based on the fundamental waveform of the electrical signals. Fig. 6 illustrates the fundamental current signal derived from the measured current. Equation (6) could then be written at fundamental pulsation $\omega_{1}$. As mentioned before, the step command pulses determine the rotational speed and therefore the fundamental pulsation $\omega_{1}$ is known. In [8], [11] it is suggested to use the sliding discrete Fourier transform (SDFT) [12]-[14] to calculate the fundamental voltage $U_{s 1}$ and current $I_{s 1}$ components based on consecutive measurement samples (shown in Fig. 6) in a computationally efficient manner. For a period of $N$ samples the $z$-domain transfer function of the $k^{t h}$ order SDFT is:

$$
\frac{1-z^{-N}}{1-e^{j 2 \pi \cdot \frac{k}{N}} \cdot z^{-1}}
$$




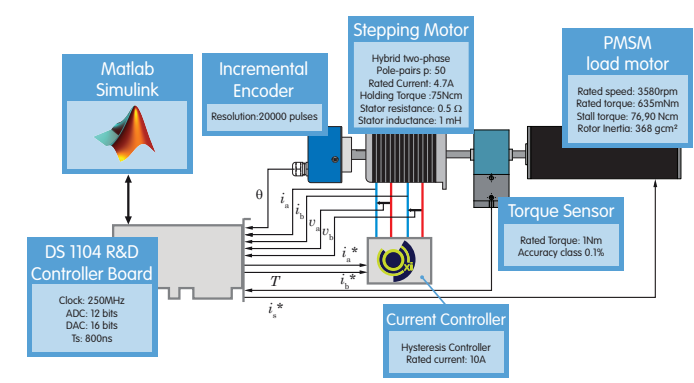

Fig. 5. Dedicated test rig set-up and parameters of the equipment

Finally the (6) is used to determine the fundamental backEMF $E_{s 1}$ based on the fundamental current $I_{s 1}$ and voltage $U_{s 1}$. According to 2 the estimated load angle $\hat{\delta}$ can then be written as:

$$
\hat{\delta}=\frac{\pi}{2}-\left(\angle\left(E_{s 1}\right)-\angle\left(I_{s 1}\right)\right)
$$

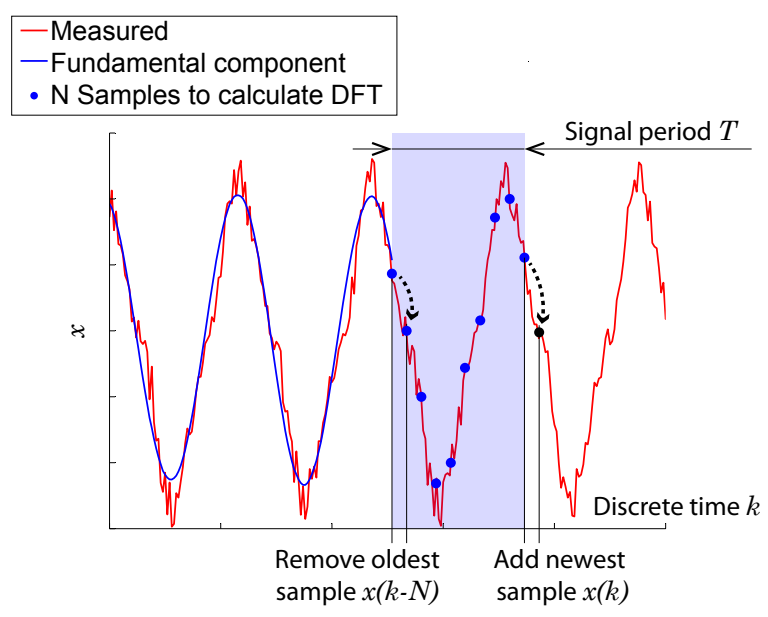

Fig. 6. Determining the fundamental waveform based on measurements

\section{LOAD ANGLE CONTROL}

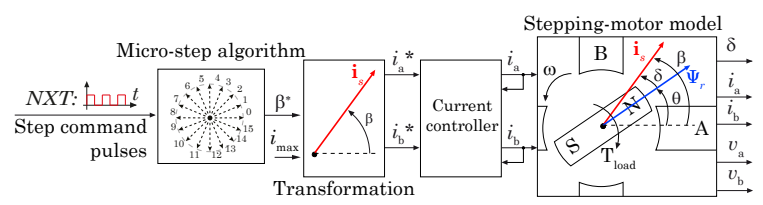

Fig. 7. Simulation model including the behavior of a hysteresis current controller [15] and the nonlinear machine behavior [10].

The typical driving principle of a stepping motor, which is comparable to a V/f control [16] used in PMSM, is illustrated in the block diagram of Fig. 7. The bulk of the stepping motor systems is driven in open loop where the angular position of the stator current vector $\mathbf{i}_{s}$ is determined by step command pulses. However, many commercial stepping motor drives [17] also allow to adjust the current vector amplitude, labeled $i_{\text {max }}$ in Fig. 7. To illustrate the effect of a current amplitude adaptation, a simulation is set-up. The simulation principle illustrated in Fig. 7 includes the model of a hysteresis current controller [15] and the nonlinear electrical and mechanical dynamics [10] of the machine depicted in Fig. 5.

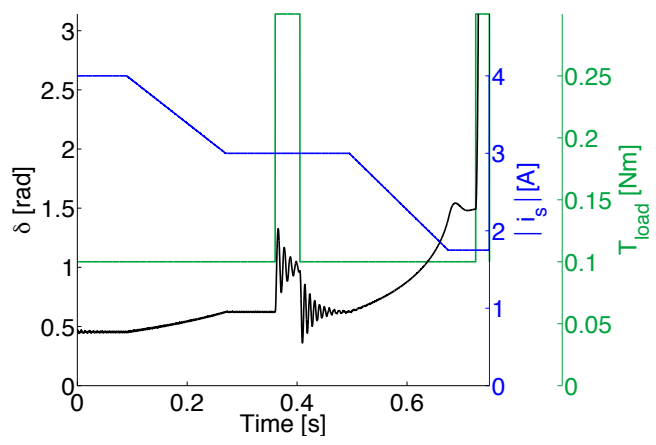

Fig. 8. Load angle behavior at a fixed speed of $375 \mathrm{rpm}$ and varying drive current and load torque

The speed, determined by the step command pulses, used for the simulation in Fig. 8 is $375 \mathrm{rpm}$. This simulation shows the load angle is approximately $0.45 \mathrm{rad}$ at a load of $0.1 \mathrm{Nm}$ and at maximum current. However, this load could still be driven at the same speed if the current is reduced. When the current is reduced to $3 \mathrm{~A}$, the load angle increases meaning a more efficient torque generation. For a given current amplitude, a sudden increase in load torque disturbance results in a higher load angle. If the load angle is low enough there is a margin to increase this angle to compensate for such sudden load torque disturbances. However, when the current is further reduced, as in Fig. 8, to $2 \mathrm{~A}$ to drive the machine at the optimal load angle value of approximately $\pi / 2 \mathrm{rad}$ (see Fig. 4) there is no margin to increase the load angle to compensate for a torque disturbance meaning the drive systems loses synchronism if a sudden torque overloads the machine. This simulation illustrates the importance of a load angle feedback. Similarly to the voltage amplitude correction applied to a V/f PMSM control in [16] the current could be adapted to control the load angle value for stepping motor drive systems. The goal of this control could either be an energy efficient drive by keeping a low current amplitude $(\delta \approx \pi / 2)$ or a robust drive by keeping the current higher $(\delta<\pi / 2)$. Hence, the load angle value quantifies both the margin for load disturbances and the torque/current ratio. However, this paper proposes a mechanism to improve the robustness against load torque disturbances even if the motor is driven at optimal load angle and low current levels.

\section{LOAD ANGLE OSCILLATIONS}

Due to the multi-toothed construction, of both rotor and stator, load angle oscillations [18] will occur even if the stepping motor is driven at a constant speed and constant current level. This oscillation will become more severe when 
the load angle approaches its optimal level $\delta_{\text {opt }}$ [18]. The optimal load angle level $\delta_{\text {opt }}$ is the maximum load angle at which no step loss occurs. The oscillations $\Delta \delta_{\text {opt }}$ at the optimal load angle level $\delta_{\text {opt }}$ are determined by measurements as indicated in Fig 9. A stepwise decrease of the current level is applied in order to find the optimal current level $i_{\text {opt }}$ just before step loss occurs. The test depicted in Fig. 9 is done for 16 different load torques and 51 rotational speed setpoints equally distributed over the operating range of the stepping motor.

The maximum deviation between the optimal load angle level and the oscillation peak of the load angle is registered as $\Delta \delta_{\text {opt }}$. When this deviation $\Delta \delta_{\text {opt }}$ is written relative to the optimal load angle $\frac{\Delta \delta_{\text {opt }}}{\delta_{\text {opt }}}$ and depicted for all measurement points Fig. 10 is obtained.

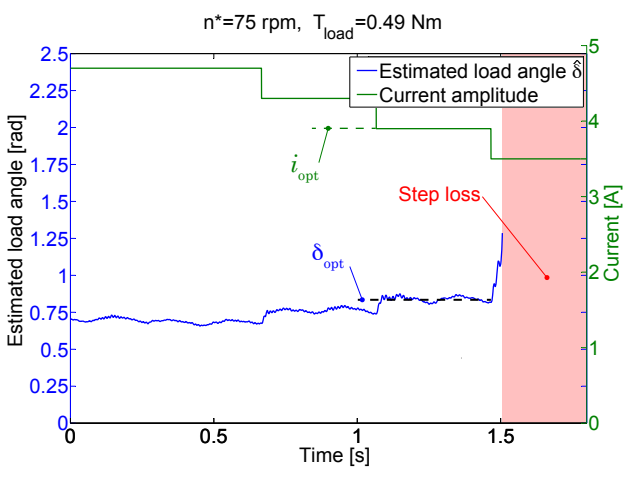

Fig. 9. Stepwise current decrease unstill stall occurs to determine the optimal load angle $\delta_{\text {opt }}$ and the oscillation at optimal load angle level $\Delta \delta_{\text {opt }}$

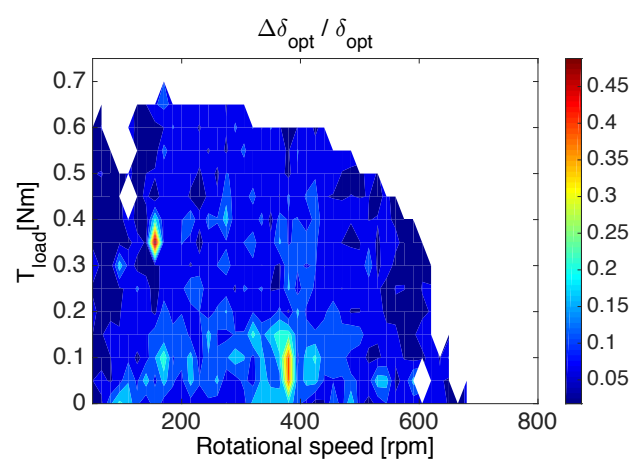

Fig. 10. Relative deviation $\frac{\Delta \delta_{\text {opt }}}{\delta_{\text {opt }}}$ between oscillation peak and optimal load angle

\section{TORQUE DISTURBANCES}

According to Fig. 10 the relative estimated load angle oscillations at optimal level $\frac{\Delta \delta_{\text {opt }}}{\delta_{\text {opt }}}$ are limited to $20 \%$ in $98 \%$ of the complete operating range of the stepping motor. This means an increase of the estimated load angle $\hat{\delta}$ above $120 \%$ of the load angle setpoint $\delta^{*}$ indicates a sudden serious load increase and possible step loss. Therefore, the load angle controller is disabled and the stepping motor is driven at maximum current whenever the estimated load angle $\hat{\delta}$ hits the level of $120 \%$ of the load angle setpoint $\delta^{*}$.

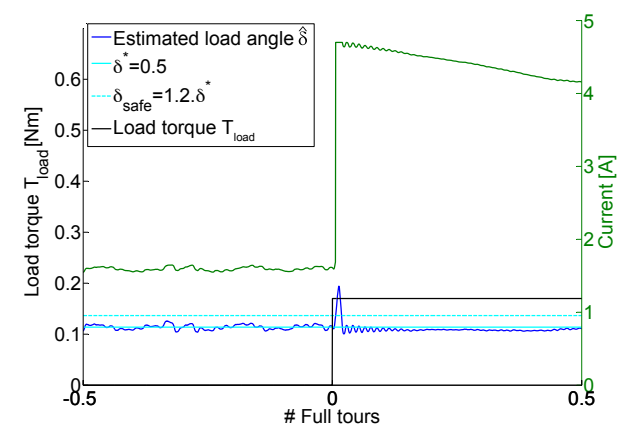

Fig. 11. Measured maximum sudden torque increase up to $T_{\text {load }}=0.17$ $\mathrm{Nm}$ for a load angle controlled regime situation at low rotational speed and no load $\left(n^{*}=75 \mathrm{rpm}\right)$

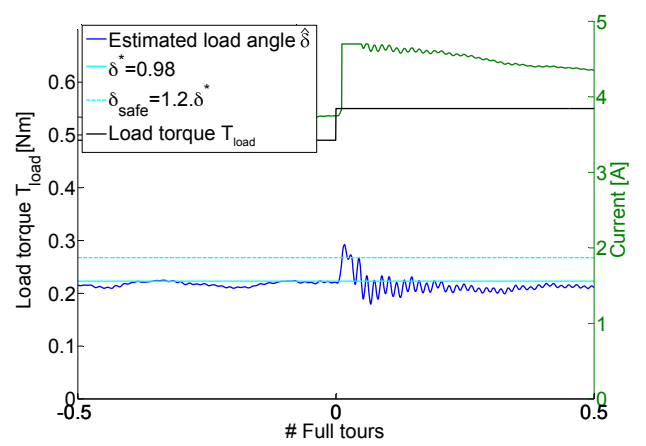

Fig. 12. Measured maximum sudden torque increase up to $T_{\text {load }}=0.55$ $\mathrm{Nm}$ for a load angle controlled regime situation at low rotational speed and maximum load $\left(n^{*}=75 \mathrm{rpm}, T_{\text {load }}=0.49 \mathrm{Nm}\right)$

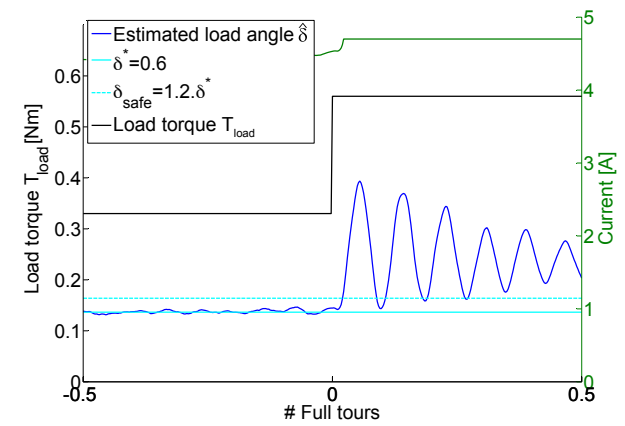

Fig. 13. Measured maximum sudden torque increase up to $T_{\text {load }}=0.56$ $\mathrm{Nm}$ for a load angle controlled regime situation at medium speed and load $\left(n^{*}=375 \mathrm{rpm}, T_{\text {load }}=0.33 \mathrm{Nm}\right)$ 


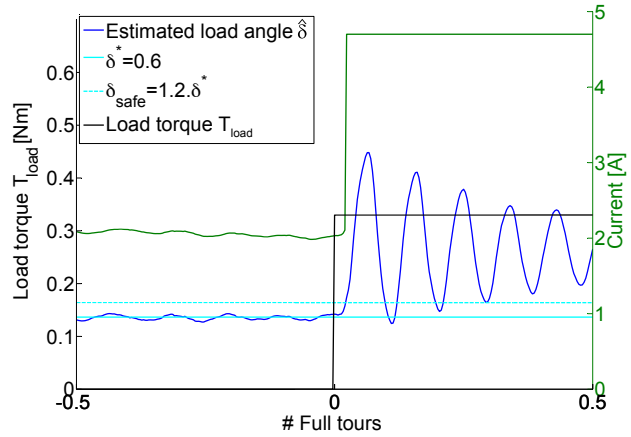

Fig. 14. Measured maximum sudden torque increase up to $T_{\text {load }}=0.33$ $\mathrm{Nm}$ for a load angle controlled regime situation at high speed and no load $\left(n^{*}=500 \mathrm{rpm}\right)$

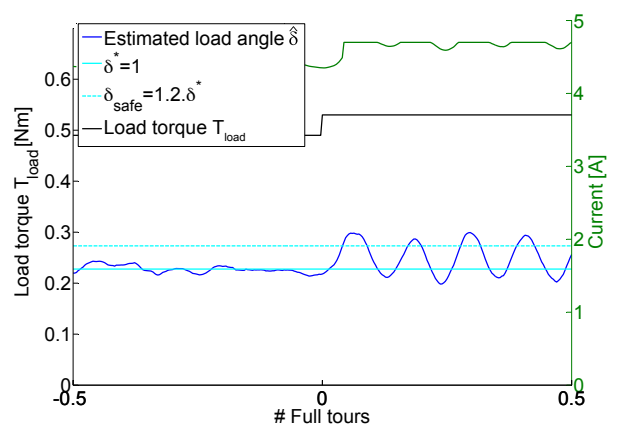

Fig. 15. Measured maximum sudden torque increase up to $T_{\text {load }}=0.53$ $\mathrm{Nm}$ for a load angle controlled regime situation at high speed and maximum load $\left(n^{*}=500 \mathrm{rpm}, T_{\text {load }}=0.49 \mathrm{Nm}\right)$

Figs. 11 to 15 show the measurement results using the proposed mechanism for five different operating points distributed over the complete operating range of the stepping motor (Fig. 5.). All the load torque increases depicted in these figures are the maximum ones. When the load torque increase would be higher this would lead to step loss. The maximum load torque increase before step loss occurs is summarised in table I. Table I also shows the maximum load torque increase if the stepping motor is driven at maximum current. In this way, the loss of robustness by applying load angle control with threshold at $120 \%$ of $\delta^{*}$ is given in this table.

TABLE I

MAXIMUM LOAD TORQUE INCREASE

\begin{tabular}{r|ccccc}
\hline & \multicolumn{5}{|c}{ Regimesituatie } \\
Toerental [tr/min] & 75 & 75 & 375 & 500 & 500 \\
Koppel $[\mathrm{Nm}]$ & 0 & 0,49 & 0,33 & 0 & 0,49 \\
\hline Max $\Delta T_{\text {last }}$ bij lasthoekregeling & 0,17 & 0,07 & 0,23 & 0,33 & 0,04 \\
Max $\Delta T_{\text {last }}$ bij $i_{\max }$ & 0,5 & 0,13 & 0,23 & 0,36 & 0,06 \\
\hline
\end{tabular}

The load angle control, and thus current decrease, will be enabled again only when the estimated load angle drops below the original load angle setpoint. This is the case in Fig. 11 where the fact that the drive current is set at its maximum level leads to a load angle drop below the setpoint $\delta^{*}$. Thereafter, the load angle controller is enabled again and the current level will be decreased again in order to obtain the more optimal load angle, meaning an optimal torque/current ratio. However, when the load increase leads to a load angle higher then $\delta^{*}$ as is the case in Fig. 13 the load angle controller will not be enabled again and the current level will be kept at its maximum level to obtain the necessary robustness.

It must be noted that Figs. 11 to 15 and table I all show the extreme situation of a sudden load torque increase. However, for gradually increasing load torques the margin will be much higher and the threshold mechanism will enhance the robustness as well as depicted in Fig. 16.

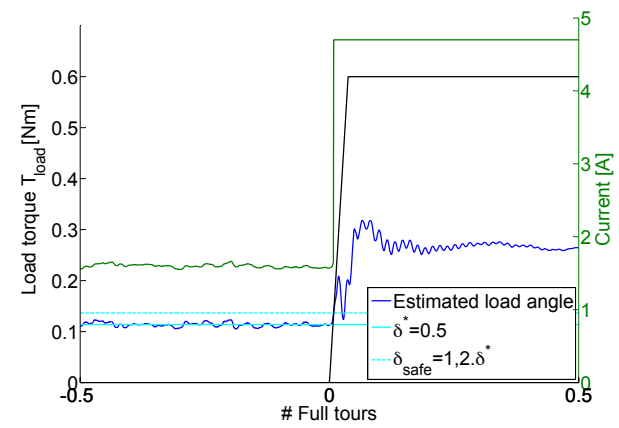

Fig. 16. Gradual load torque increase to $T_{\text {load }}=0.6 \mathrm{Nm}$ for a load angle controlled regime situation at low speed and no load $\left(n^{*}=75 \mathrm{rpm}\right)$

\section{CONCLUSIONS}

The load angle determines the torque/current ratio of the stepper motor drive. In this paper, the load angle is estimated based on fundamental components of the measured phase current and voltage. The estimator used in this paper does not need tuning and only relies on easily measurable electrical parameters. Subsequently, the estimated load angle is to reduce the current so that an optimal torque/current ratio is obtained. This optimised current level diminishes the robustness to load torque disturbances which could result in step loss. However, in this paper a threshold mechanism is proposed to disable the load angle optimisation and drive the motor at maximum current to avoid step loss. Measurements prove the effect of this mechanism on the robustness of the stepping motor drive system.

\section{REFERENCES}

[1] C. Kuert, M. Jufer, and Y. Perriard, "New method for dynamic modeling of hybrid stepping motors," in Conference Record of the Industry Applications Conference, 37th IAS Annual Meeting, vol. 1, 2002, pp. 6-12.

[2] M. Bodson, J. S. Sato, and S. R. Silver, "Spontaneous speed reversals in stepper motors," IEEE Transactions on Control Systems Technology, vol. 14 , no. 2, pp. 369-373, 2006. 
[3] S. Derammelaere, B. Vervisch, J. Cottyn, B. Vanwalleghem, P. Cox, F. De Belie, K. Stockman, L. Vandevelde, and G. Van Den Abeele, "The efficiency of hybrid stepping motors: analyzing the impact of control algorithms," IEEE Industry Applications Magazine, vol. 20, no. 4, pp. 50-60, 2014. [Online]. Available: http://hdl.handle.net/1854/LU4662236 http://dx.doi.org/10.1109/MIAS.2013.2288403

[4] S. Ajdukovic, B. Kuzmanovic, and P. Crnosija, "Microcomputer implementation of optimal algorithms for closed-loop control of hybrid stepper motor drives," IEEE Transactions on Industrial Electronics, vol. 47, no. 6, pp. 1319-1325, 2000.

[5] F. Betin, D. Pinchon, and G.-A. Capolino, "Fuzzy logic applied to speed control of a stepping motor drive," IEEE Transactions on Industrial Electronics, vol. 47, no. 3, pp. 610-622, 2000.

[6] Q. N. Le and J.-W. Jeon, "Neural-Network-Based Low-Speed-Damping Controller for Stepper Motor With an FPGA," IEEE Transactions on Industrial Electronics, vol. 57, no. 9, pp. 3167-3180, 2010.

[7] K.-H. Tsui, N. Cheung, and K.-W. Yuen, "Novel Modeling and Damping Technique for Hybrid Stepper Motor," IEEE Transactions on Industrial Electronics, vol. 56, no. 1, pp. 202-211, Jan. 2009.

[8] S. Derammelaere, C. Debruyne, F. De Belie, K. Stockman, and L. Vandevelde, "Load angle estimation for two-phase hybrid stepping motors," IET Electric Power Applications, vol. 8, no. 7, pp. 257-266, Aug. 2014

[9] P. Vas, Sensorless vector and direct torque control. New York: Oxford University Press, 1998.

[10] S. Derammelaere, B. Vervisch, F. De Belie, J. Cottyn, G. Van den
Abeele, P. Cox, K. Stockman, and L. Vandevelde, "A nonlinear and linear model of a hybrid stepping motor," in ELECTRIMACS, 2011. [Online]. Available: http://hdl.handle.net/1854/LU-1909480

[11] S. Derammelaere and K. Stockman, "US provisional application, entitled Systems and methods for position detection," 2013.

[12] E. Jacobsen and R. Lyons, "The sliding DFT," IEEE Signal Processing Magazine, vol. 20, no. 2, pp. 74-80, 2003.

[13] _ _ "An Update to the Sliding DFT," IEEE Signal Processing Magazine, vol. 21, no. 1, pp. 110-111, 2004.

[14] K. Duda, "Accurate, Guaranteed Stable, Sliding Discrete Fourier Transform [DSP Tips \& Tricks]," IEEE Signal Processing Magazine, vol. 27, no. 6, pp. 124-127, 2010.

[15] PsiControl Mechatronics, "Datasheet: Oxi Functional Description," Ieper, Belgium, pp. 1-63, 2008.

[16] S.-C. Agarlita, C.-E. Coman, G.-D. Andreescu, and I. Boldea, "Stable V/f control system with controlled power factor angle for permanent magnet synchronous motor drives," IET ELECTRIC POWER APPLICATIONS, vol. 7, no. 4, pp. 278-286, Apr. 2013.

[17] ON Semiconductor, "Micro-Stepping Stepper Motor Bridge Controller," p. $41,2011$.

18] S. Derammelaere, B. Vervisch, F. Verbelen, and K. Stockman, "Torque ripples in stepping motor driven systems," in EPE ECCE Europe, Geneva (Switzerland), 2015. 